Published in : Journal of applied entomology (2005), vol.129, iss. 1, p. 6-11

Status : Postprint (Author's version)

\title{
Long run behaviour of Pacific-Basin stock prices
}

\author{
Corhay $\mathrm{A}^{[1]}$, Tourani Rad A ${ }^{[1]}$ Urbain J-P ${ }^{[2]}$
}

\author{
${ }^{[1]}$ Department of Business Administration, Boulevard du Rectorat 7, University of Liege, 4000 Liege, \\ Belgium \\ ${ }^{[2]}$ Department of Economics, University of Limburg, P.O. Box 616, 6200 MD Maastricht, The \\ Netherlands
}

In this paper, we investigate the long run relationship among five major Pacific-Basin stock markets. We focus on the common long run behaviour of their stock price indices over a sample period of 20 years. Using cointegration theory, we find that while there exists a rather integrated Pacific Basin financial area, the regional aspects (Asian versus Pacific) play important roles.

\section{Introduction}

There has been an increasing interest in the nature of relationship among major Western financial capital markets during the last two decades. This interest has been aroused mainly because of the increase in the flow of capital across countries which in turn is mainly due to market deregulation measures, technological developments in communications and trading systems, and the emergence of innovative financial products. International capital market relationship has important implications for the macroeconomic policies to deal with trade and fiscal imbalances among countries, theoretical studies of international asset pricing models, and financial policies of multinational companies. While the interdependence of Western capital markets and of course that of Japan has been the subject of extensive research, there is a small body of research that examines the interrelationship of PacificBasin stock markets. The share of the latter markets in the world stock market capitalization has grown from $14 \%$ in 1972 to $47 \%$ in 1988. The total market capitalization of these countries is greater than that of the European markets or the US markets (Solnik, 1991). The growing economic importance of the Pacific-Basin countries has, however, recently attracted the attention of the academic community. As these markets function in different cultural, institutional and regulatory circumstances than those of their Western counterparts, a substantial amount of research is still required to contribute to a better understanding of many relevant issues. The objective of this study is to observe whether there is a common long-term trend among the stock prices of the five largest and least restricted Pacific-Basin markets over a period of twenty years.

To study the interrelationship among national capital markets several approaches can be used. One approach is a joint test of the market integration and the validity of a particular asset pricing model. Different versions of the mean-variance capital asset pricing model were used by Solnik (1994), Stehle (1977), Errunza and Losq (1985), and Brennen and Schwartz (1986); the arbitrage pricing model by Cho, Eun and Senbet (1986) and Gultekin, Gultekin and Penati (1989); and consumption-based asset pricing model by Weatley (1988) and Cumby (1990) to investigate the integration of international capital markets. A more recent approach is the use of time-varying volatility to investigate the interrelationship of stock prices and their volatilities in various markets and their transmission from one market to another. Hamao, Masulis and $\mathrm{Ng}$ (1990), for instance, used an autoregressive conditional heteroscedastic mode! and found empirical support for the integration of the three major international stock markets: the USA, the UK and Japan. King and Wadhwani (1990) found that the covariance of stock returns among different stock exchanges has increased after the crash of 1987. Eun and Shim (1989) using the vector auto regression (VAR) method investigated the interaction among nine major stock markets. They showed how markets react to innovations in a specific market and their results indicate the US market has the major impact on the international capital market. Jeon and Von Furstenberg (1990) also used VAR analysis and found a significant structural change took place in four major world stock markets since the stock market crash of 1987, and an international co-movement of stock market has increased since then.

In the context of Pacific-Basin studies, Baily and Stulz (1990) have shown that a US investor can reduce risk of his portfolio by up to $50 \%$ by investing in Pacific-Basin equities. Campbell and Hamao (1990) argue that the US and Japanese markets are highly integrated though not perfectly. Results of studies by Harvey (1991) and Cho et al. (1986) are, however, less convincing and their evidence 
Published in : Journal of applied entomology (2005), vol.129, iss. 1, p. 6-11

Status : Postprint (Author's version)

reveals that the Japanese and other Asian markets are not well integrated in the world markets. Park and Fatemi (1993) show that these markets are indeed minimally integrated, offering substantial potential for risk reduction.

Overall, one can nevertheless expect substantial links between stock prices of different stock markets in this area. It is also clear (as shown in Figs 1 and 2 of the next section) that we can face two distinct types of links between these indices. The first potential one is typically related to the volatile behaviour of stock indices while the other is related to the 'trending behaviour' of the series. In this paper, we shall be concerned with the latter. To the best of our knowledge, this is the first time this approach is applied to Pacific-Basin countries. In particular, our approach here is to explore the degree to which stock prices of five important and active Pacific-Basin markets, namely those of Australia, Japan, Hong Kong, New Zealand and Singapore, exhibit common long-term stochastic trends. For this purpose, and following previous research in this area (Corhay et al., 1992, 1993; Kasa, 1992) we shall make an extensive use of the notion of cointegration developed, among others, by Engle and Granger (1987). Since cointegration implies that non-stationary times series (such as stock prices) move stochastically together towards some long run stable relationship, the existence of cointegrating relationships among various stock prices has a direct implication in terms of the existence of common trends among these series.

The organization of the paper is as follows. In Section II, we briefly present the econometric tools that are used in the empirical analysis. Section III presents the data definition and some univariate statistics. In Section IV, we investigate the existence of common stochastic trends among the series. A final section concludes.

\section{Methodology}

We recall here some of the basic notions that we are using in the empirical analysis and can be found in the recent surveys of Dolado et al (1990), Banerjee and Hendry (1992).

We will focus on first order nonstationary integrated process (I(1) processes), i.e. processes which require first differences to become weakly stationary. Cointegration relationships, which allow the description of stable long-run stationary relationship among integrated variables, are then defined as (independent) linear combinations of these variables achieving stationarity. When a meaningful interpretation can be attached to this linear combination it implies that, under the hypothesis of cointegration, the series do not drift too much apart and are tied together by some long run equilibrium relationship.

In order to sketch (for rigorous and detailed developments see Johansen, 1991) the relationship between the existence of cointegration and that of common stochastic trends, we consider a Adimensional I(1) vector time series $\left\{x_{t}\right\}$. For simplicity we assume a unique (up to a scalar factor) linear combination of the x's which is weakly stationary and denoted by $\beta^{\prime} x_{t}$. From these assumptions we can write down the multivariate Wold representation of $\Delta x_{t}$ :

$$
\Delta x_{t}=\sum_{i=0}^{\infty} C_{i} \varepsilon_{t-i}=C(L) \varepsilon_{t}
$$

with $\mathrm{C}(L)$ a $k x k$ matrix polynomial in the lag operator with exponentially decreasing weights (matrices) $C_{i}$. We can decompose $C(L)$ as follows

$$
\sum_{i=0}^{\infty} C_{i} L^{i}=\sum_{i=0}^{\infty} C_{i}+(I-L) \sum_{i=1}^{\infty}\left(-\sum_{j=i}^{\infty} C_{j}\right) L^{i-1}
$$

so that $\Delta \mathrm{x}_{\mathrm{t}}$ can be rewritten as

$$
\Delta x_{t}=C(1) \varepsilon_{t}+\Delta C^{*}(L) \varepsilon_{t}
$$

with $C^{*}(L)$ is a matrix lag polynomial defined $C^{*}(L)=\sum_{i=1}{ }^{\infty} C_{i} * L^{i-1}$ where $C_{i}^{*}=-\sum_{j=1}{ }^{\infty} C_{j}$, $C(1)=\sum_{i=0}{ }^{\infty} C_{i}$ and where it can be shown (see for example Engle and Granger. 1987) that $C^{*}(L)$ is invertible. If we now integrate both sides of the last equation we obtain:

$$
x_{t}=C(1) \sum_{s=1}^{t} \varepsilon_{s}+C^{*}(L) \varepsilon_{t}+\left(x_{0}-C^{*}(L) \varepsilon_{0}\right)
$$

This representation corresponds to the Common Trend Representation of Stock and Watson (1988). If we premultiply Equation 4 by $\beta$ ', we get 
Published in : Journal of applied entomology (2005), vol.129, iss. 1, p. 6-11

Status : Postprint (Author's version)

$$
\beta^{\prime} x_{t}=\beta^{\prime} C(1) \sum_{s=1}^{t} \varepsilon_{s}+\beta^{\prime} C^{*}(L) \varepsilon_{t}+\beta^{\prime}\left(x_{0}-C^{*}(L) \varepsilon_{0}\right)
$$

From this, it is clear that for the linear combination $\beta^{\prime} x$, to be weakly stationary, we have to require that $\beta$ lies in the left null space of $\mathrm{C}(1)$, i.e. that $\beta^{\prime} C(1)=0$. This gives conditions on the rank of $\mathrm{C}(1)$ for cointegration to hold, namely that of the numbers of common (stochastic) trends in the system. Alternatively, we can consider a pth order vector auto-regression (VAR) model for $\mathrm{x}_{\mathrm{t}}$.

$$
A(L) x_{t}=\varepsilon_{\mathrm{t}}
$$

with

and where $\varepsilon_{\mathrm{r}}$ denotes a k-dimensional $\quad$ normal variate with mean zero and nonsingular, p.d.s. covariance matrix $\sum$ It is assumed that the roots of the implicit characteristic polynomial are outside or on the unit circle. From Equations 1 and 5 we have $A(L) C(L)=I_{n}$ $=(1=\mathrm{L}) \mathrm{I}_{\mathrm{n}}$ with $\mathrm{I}_{\mathrm{n}}$ the identity matrix, and thus $\mathrm{A}(1) \mathrm{C}(1)=0$ which implies that we can write $A(1)=\alpha \beta^{\prime}$. The number of cointegrating vectors can thus be based on the rank of ,4(1) or on that of C(1). In particular, the analysis of the rank of .4(1) gives the base of Johansen's procedure (Johansen, 1988, 1991; Johansen and Juselius, 1990) and corresponds to the number of cointegrating vector, while Stock and Watson (1988) base their procedure on the rank of $\mathrm{C}(1)$, i.e. on the number of common stochastic trends in the system.

Thus taking Equation 5 as a starting point, Johansen (1988, 1991) and Johansen and Juselius (1990) have proposed a maximum likelihood approach for both the problem of estimating and testing the number of cointegrating relationships among the components of a k-vector $x_{t}$ of variables. Equation 5 can be reparameterized in vector autoregressive error correction form:

$$
\Delta x_{t}=\sum_{i=1}^{p-1} \Gamma_{i} \Delta x_{t-i}+\Gamma_{p} x_{t-p}+\varepsilon_{t}
$$

$\Gamma_{\mathrm{i}}=-\mathrm{I}+A_{1}+\ldots+\mathrm{A}_{\mathrm{i}}$ with $\mathrm{i}=1, \ldots, p . \Gamma_{\mathrm{i}}$, are here interim multipliers. If $r_{p}$ has full rank, then $\mathrm{x}$, is stationary and all the components are $\mathrm{I}(0)$. The interesting cases arise when $\operatorname{rank}\left(\Gamma_{\mathrm{p}}\right)=\mathrm{r}<\mathrm{k}$ in which case there are $k-r$ unit roots in the system and $r$ linear combinations which are stationary, i.e. there are $\mathrm{r}$ cointegrating relationships. $\Gamma_{\mathrm{p}}$ can then be written as $-\alpha \beta^{\prime}$ where both $\alpha$ and $\beta$ are (k x r) matrices of full column rank. The $\mathrm{r}$ rows of $\beta^{\prime}$ are the $\mathrm{r}$ cointegrating vectors in the different equations. The ML estimate of a basis of the cointegrating space is given by the empirical canonical variates of $x_{t}$ $-p$ with respect to $x_{t}$ corrected for the short run dynamic and the deterministic components. ${ }^{1}$ The number of cointegrating relationships is given by the number of significant canonical correlations. Their significance can be tested by means of a sequence of likelihood ratio (LR) tests whose limiting distribution is expressed in terms of vector Brownian motions (see Johansen, 1988, 1991). Two possible test statistics can be used for the hypothesis of the existence of $r$ cointegrating vectors. First the so-called trace test, i.e. the LR test statistic for the hypothesis that there are at most $\mathrm{r}$ cointegrating vectors, given by:

$$
-2 \log (Q)=-T \sum_{i=r+1}^{k} \log \left(1-\lambda_{i}\right)
$$

where $\lambda_{r}+1, \ldots, \lambda_{k}$ are the $k-r$ smallest squared canonical correlations. An alternative is to use the maximum eigenvalue test which seeks to compare the hypothesis of $r$ cointegrating vectors against that of $r$ - 1 cointegrating vectors. The LR test statistic for this hypothesis is given by:

$$
-2 \log (Q)=-T \log \left(1-\lambda_{r}\right)
$$

The limiting distribution of $2 \log (\mathrm{Q})$, which is a function of a $k-r$ dimensional vector Brownian motion, is not independent of the unknown drift term (Johansen and Juselius, 1990), Critical values have been tabulated by Johansen and Juselius (1990) for various hypotheses concerning the behaviour of the deterministic components. The distributions of both the trace and the eigenvalue tests in the case without drift have broader tails than in the case with drift. Empirical applications should therefore carefully investigate the presence or absence of trends in the long run. Once the number of cointegrating relationships has been determined, it is possible to test particular hypotheses concerning $\alpha$ 
Published in : Journal of applied entomology (2005), vol.129, iss. 1, p. 6-11

Status : Postprint (Author's version)

and $\beta$ using standard $\chi^{2}$ distributed LR tests.

\section{Empirical results}

Data

We have chosen the five Pacific-Basin markets which are the largest and have least regulatory restrictions. These are Australia, Hong Kong, Japan, Singapore and New Zealand. We used Datastream International (a UK incorporated data service company) as our source of data.

The national stock price indices are: All Ordinary Shares for Australia, Hang Seng Bank for Hong Kong, Nikkei Dow Jones Average (225) for Japan, the Barclays Industrial for New Zealand and Straits Times for Singapore. The period of investigation spans from February 1972 to February 1992 and involves a sample of 261 monthly observations. Prior to the empirical analysis, the series were transformed into natural logs. These are depicted in Figs. 1 and 2.

\section{Univariate properties of the data}

As clearly shown on these figures, the series are highly trending variables and hence likely I(1) processes. In order to test for the presence of stochastic nonstationarity in our data, we first investigate the integration order of our individual times series using some well-known unit root test including augmented Dickey-Fuller (ADF) tests and Phillips and Perron's (1988) non-parametrically modified Dickey-Fuller test. The ADF test is based on the following regression model

$$
\Delta y_{t}=\alpha+\mu t+\rho y_{t-1}+\sum_{i=1}^{p} \psi_{i} \Delta y_{t-i}+\varepsilon_{t}
$$

(V)

which is estimated by ordinary least squares (OLS). The normalized bias $(T(\hat{\rho}))$, where $\mathrm{T}^{*}$ is the sample size, or the $t$-tests for $\rho=0$ is computed.

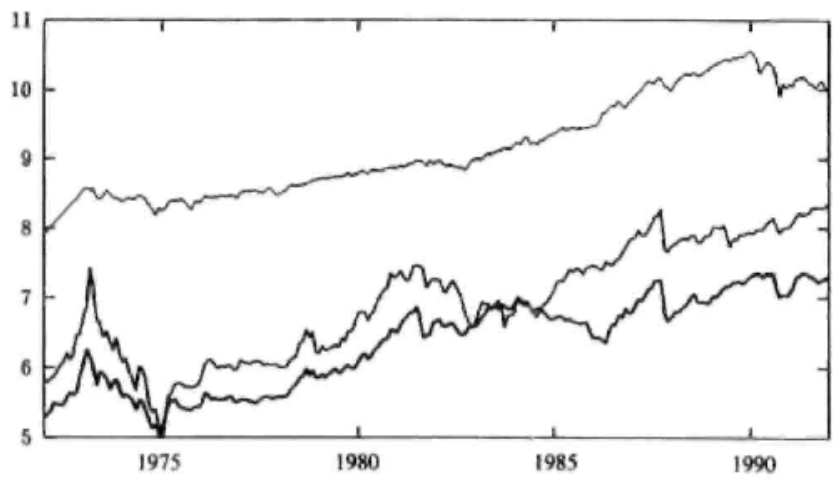

Fig. 1. Logs of the stock price indices: (-----) Japan, (------) Hong Kong and (------) Singapore

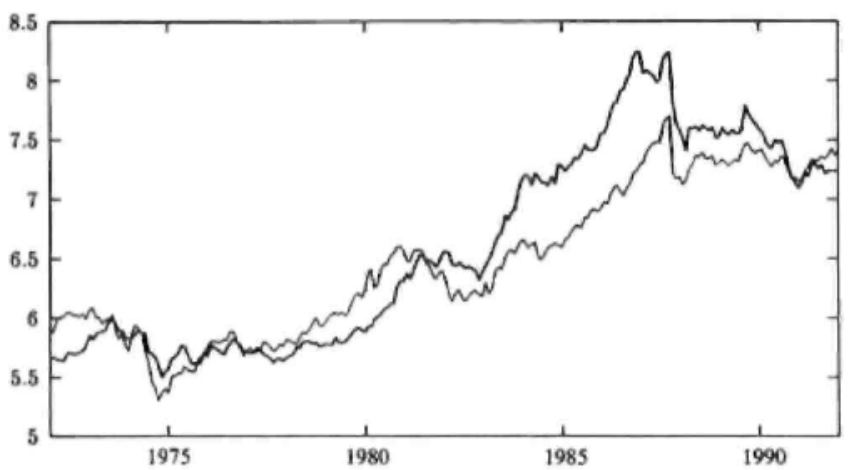


Published in : Journal of applied entomology (2005), vol.129, iss. 1, p. 6-11

Status : Postprint (Author's version)

Fig. 2. Logs of the stock price indices: (-----) Australia and (-----) New Zealand

Under the null hypothesis of a unit root, the limiting distribution of these test statistics are non-standard since the empirical moments of unit processes generally converge to random variables instead of constants. Several assumptions concerning the deterministic components can also be tested using onesided (F-type) tests whose critical values are given in Fuller (1976). The limiting distribution crucially depends on the deterministic components of !he univariate series. Critical values are tabulated in Fuller (1976). Phillips-Perron's (1988) modification to the Dickey and Fuller test (based on Equation 1 without lagged first differences) is motivated by the fact that the ADF tests are only valid under the crucial assumption of i.i.d. processes. In practice, it may be more realistic to allow for some dependence among the $\varepsilon_{\mathrm{t}}$ 's. In that case the asymptotic distribution changes. Phillips (1987) and Phillips and Perron (1988) have weakened the i.i.d. assumption by allowing for some serial correlation and heteroskedasticity. In the computation of these modified statistics, we used the Newey and West (1987) non-negative long-run variance estimator. The asymptotic limiting distribution is the same as that of the $x$ tests tabulated by Fuller (1976).

From the figures reported above, it clearly appears that most of our series are likely to possess some deterministic trend component or might even be characterized as trend stationary processes. Therefore, we implicitly followed the sequential testing procedure proposed by Perron (1988) which aims to start from a quite general specification with both trend and constant terms. The first hypothesis which is thus tested is that of a random walk (unit root) with drift against a trend stationary process. In the case of non-rejection, we then test for the significance of the trend term and so on. The final hypothesis to be tested in this sequence (if all the previous less restrictive hypotheses have not been rejected) is the driftless random walk against the simple zero-mean stationary AR(1) process. The results of the unit root tests are reported in Table 1. For both ADF-type and Phillips-Perron type statistics, the lag truncation was set at four after having scrutinized the autocorrelation function of the first differences. The following notation is used: $\mathrm{T}$ is the usual t-test based on Equation 7 without trend term and $\tau$ is the $t$-test based on Equation 7 with trend term. The $\Phi_{i} i=1,2,3$ are one sided F-type statistics respectively testing the null hypotheses of(i) $(, \rho)=(0,1)$ in Equation 7 without trend, for $\left(\Phi_{1}\right),(i i)(, \beta, \rho)=(0,0,1)$ in Equation 1 with trend $\left(\Phi_{2}\right)$, and $(i i i)(, \beta, \rho)=(, 0,1)$ in Equation 7 with trend. The ' $Z$ ' versions reported in Table 1 have the same interpretation but are computed with the Phillips-Perron nonparametric correction instead of the lag augmentation.

Table 1. Unit root tests levels

\begin{tabular}{|c|c|c|c|c|c|c|}
\hline Test statistic & Japan & Hong Kong & Singapore & Australia & New Zealand & $95 \%$ critical value \\
\hline$\tau$ & -1.19 & -2.31 & -1.04 & -0.37 & -0.77 & -2.89 \\
\hline$\tau$ & -1.59 & -2.81 & -2.99 & -2.68 & -1.52 & -3.45 \\
\hline $\begin{array}{l}\Phi_{1} \\
\Phi_{2} \\
\Phi_{3}\end{array}$ & $\begin{array}{l}4.53 \\
3.70 \\
1.60\end{array}$ & $\begin{array}{l}2.11 \\
3.88 \\
4.25\end{array}$ & $\begin{array}{l}1.43 \\
3.60 \\
4.48\end{array}$ & $\begin{array}{l}0.81 \\
3.14 \\
3.96\end{array}$ & $\begin{array}{l}1.07 \\
1.29 \\
1.61\end{array}$ & $\begin{array}{l}4.71 \\
4.88 \\
6.49\end{array}$ \\
\hline $\mathrm{Z}(\tau)$ & -0.99 & -2.56 & -1.14 & -0.28 & -0.70 & -2.89 \\
\hline $\mathbf{Z}(\tau)$ & -1.78 & -3.05 & -2.88 & -2.80 & -1.57 & -3.45 \\
\hline $\begin{array}{l}\mathrm{Z}\left(\Phi_{1}\right) \\
\mathrm{Z}\left(\Phi_{2}\right) \\
2\left(\Phi_{3}\right)\end{array}$ & $\begin{array}{l}3.97 \\
3.39 \\
1.75\end{array}$ & $\begin{array}{l}2.25 \\
4.08 \\
4.65\end{array}$ & $\begin{array}{l}1.70 \\
3.44 \\
4.16\end{array}$ & $\begin{array}{l}0.68 \\
3.42 \\
4.48\end{array}$ & $\begin{array}{l}1.33 \\
1.54 \\
1.78\end{array}$ & $\begin{array}{l}4.71 \\
4.88 \\
6.49\end{array}$ \\
\hline
\end{tabular}

As shown in this table we are not able to reject the null of a unit root with drift against the trend stationary alternative hypothesis in our five series. The same battery of tests applied to the first differences confirms that our data set contains three I(1) (possibly with some deterministic terms) variables. The next step of the analysis is then naturally to investigate the potential cointegration properties of these data. In the case where cointegration is effectively not rejected by our data set, we will then be able to conclude about the existence (or non existence) of common long run behaviour. 
Published in : Journal of applied entomology (2005), vol.129, iss. 1, p. 6-11

Status : Postprint (Author's version)

Once we have been unable to reject the null hypothesis of unit roots, we can build multivariate models which will enable us to investigate the presence or absence of cointeg-rating relationships in our data set. Instead of first computing bivariate cointegration regressions in the Engle and Granger (1987) spirit, we directly consider the five series jointly in a vector error correction model (VECM) such as Equation 6. In a first stage, we allowed a linear trend to enter the cointegrating vector. Since an LR test for the null hypothesis of the absence of a linear trend in the long-run relationship cannot be rejected by the data, our final specification of the VECM consist of allowing for an unrestricted constant in the short run in order to capture the trending behaviour of the data series. In order to take into account the potential effect of the October 1987 crash, we introduced a dummy variable denoted by D87 which is equal to one in 1987:11 and zero to elsewhere.

The specification of the lag length of the VAR is tested sequentially using likelihood ratios test statistics. These are reported in Table 2 where LR(7/8) stands for the LR test testing the validity of a seventh order VAR (under the null) against an eighth order VAR. According to the results reported in Table 2, we finally chose to investigate a VAR of order six given a 5\% critical value of a $37.66\left(\chi^{2}(25)\right.$ under the null).

The computation of Johansen's trace and maximum eigenvalue tests are given in Table 4, along with the estimates of the eigenvalues, normalized eigenvectors and weights. Table 3 reports some statistics on the error processes where it clearly appears that both the normality hypothesis and the absence of conditional heteroskedastic-ity are rejected by the data. We will come to these characteristics later on. $\mathrm{BJ}$ is the usual Bera and Jarque normality test, BP is a sixteenth order Box Pierce test for serial correlation, and $\mathrm{ARCH}(6)$ is the usual LM test for sixth order ARCH effects in the residuals. As shown in Table 4, we may not reject the hypothesis of a single cointegrating vector among our five variables. The normalized coefficients are given in the first column of the $\beta$ matrix. The time series profile of the cointegrating vector is given in Fig. 3.

Although the coefficients of this cointegrating vector are not easily interpretable as such, their relative magnitude is however informative on the respective role of the countries in this financial area. In particular, we see that both Singapore and New Zealand are likely to play a very minor role in the long run.

This is tested explicitly in Table 5 where we have tested two kinds of hypotheses:

(1) The absence the corresponding country in the cointeg-rating vector (i.e. its presence or absence in this 'long run' attractor)

(2) Whether the cointegrating vector appears as significant in the equation for the corresponding country.

This last hypothesis is quite interesting with respect to its behavioural content. The immediate interpretation of a zero coefficient in the $\alpha$ vector is that of exogeneity of the corresponding variables for the long-run parameters (see Johansen, 1992, Urbain, 1992). Another interpretation in the VECM set-up is in terms of long-run Granger causality links. One can effectively show that if the cointegrating vector does not appear in a given equation, this means that the lagged levels do not influence the evolution of the corresponding variables, and that the latter is not caused, in the long run, by the variables entering in the cointegrating vector.

Table 2. LR tests for the lag order

\begin{tabular}{ll}
\hline LR test statistic: & $\chi^{2}(25)$ under $H_{0}$ \\
\hline $\operatorname{LR}(7 / 8)$ & 21.139 \\
$\operatorname{LR}(6 / 7)$ & 31.941 \\
$\operatorname{LR}(5 / 6)$ & 43.531 \\
$\operatorname{LR}(4 / 5)$ & 38.323 \\
$\operatorname{LR}(3 / 4)$ & 39.111 \\
$\operatorname{LR}(2 / 3)$ & 37.591 \\
$\operatorname{LR}(1 / 2)$ & 51.106 \\
\hline
\end{tabular}

Table 3. Statistics on the error processes

\begin{tabular}{llllll} 
Countries & BP(16) & Skewness & $\begin{array}{l}\text { Excess } \\
\text { kurtosis }\end{array}$ & BJ-normality & ARCH(6) \\
\hline Japan & 10.03 & -0.776 & 3.089 & 117.53 & 50.08 \\
Hong Kong & 16.17 & 0.594 & 5.233 & 283.122 & 7.20 \\
Singapore & 8.56 & 0.038 & 1.443 & 20.536 & 12.96
\end{tabular}


Published in : Journal of applied entomology (2005), vol.129, iss. 1, p. 6-11

Status : Postprint (Author's version)
Australia
19.15
$-0.057$
0.450
2.117
6.499
New Zealand 20.25
0.326
1.135
16.847
6.263

Table 4. ML cointegration analysis

$\mathbf{k}=\mathbf{6}$

\section{Eigenvalues}

0.1320

0.0870

0.0560

0.0330

0.0030

\begin{tabular}{ll}
\hline Trace test & $\mathrm{H}_{0}$ \\
0.626 & $\mathrm{r} \leq$ \\
8.560 & $\mathrm{r} s$ \\
22.159 & $\mathrm{r} s$ \\
43.725 & $\mathrm{r}<$ \\
$77.259 *$ & $\mathrm{r}=$
\end{tabular}

Normalized reintegrating vectors: $\beta$ matrix

$\begin{array}{llllll}\text { Japan } & 1.000 & 0.117 & 3.634 & 0.343 & 0.964 \\ \text { Hong Kong } & 0.841 & -0.110 & -4.065 & 2.575 & -0.682 \\ \text { Singapore } & -0,141 & 0.017 & 0.367 & -5.082 & -0.605 \\ \text { Australia } & -2.010 & 1.000 & 2.359 & 0.552 & -0.981 \\ \text { New Zealand } & 0.015 & -0.800 & -0.979 & 0.759 & -0.158 \\ \text { Weights: } \alpha \text { matrix } & & & & & \\ \text { Japan } & -0.058 & -0.033 & -0,003 & 0.003 & 0.001 \\ \text { Hong Kong } & -0.126 & 0.027 & 0.016 & -0.005 & 0.002 \\ \text { Singapore } & -0.014 & 0.041 & 0,004 & 0.004 & 0.003 \\ \text { Australia } & 0.027 & -0.043 & 0.003 & -0.002 & 0.002 \\ \text { New Zealand } & -0.011 & -0,003 & -0.005 & -0.007 & 0.002 \\ \end{array}$

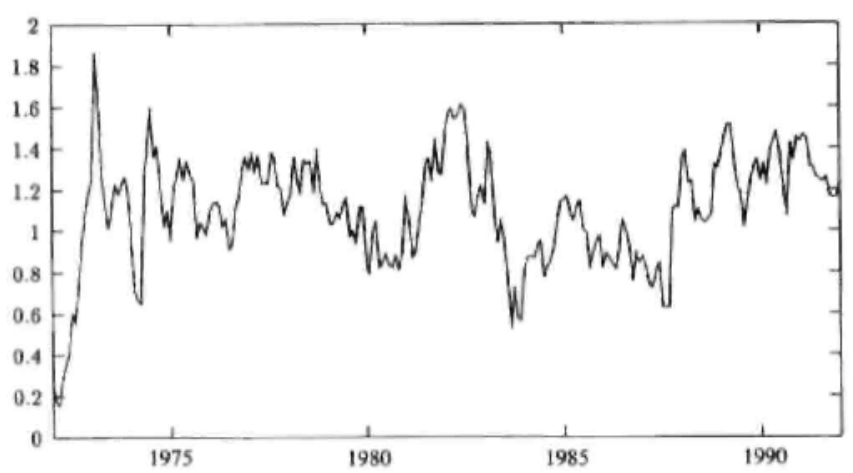

Fig. 3. First cointegrating vector

Table 5. Restrictions on the cointegrating vector and 'long run causality

\begin{tabular}{lll}
\hline Country & $\begin{array}{l}\left.\text { Restriction on } \beta \chi^{2} \wedge\right) \\
\text { under } \mathrm{H}_{0}\end{array}$ & $\begin{array}{l}\text { Restriction on } \alpha \text { (long } \\
\text { run causality) } \chi^{2}(1) \\
\text { under } H_{0}\end{array}$ \\
\hline Japan & $11.61^{*}$ & $6.46^{*}$ \\
Hong Kong & $9.84^{*}$ & $7.02^{*}$ \\
Singapore & 0.59 & $3.86^{*}$ \\
Australia & $9.72^{*}$ & 1.02 \\
New Zealand & 0.02 & 2.97 \\
\hline
\end{tabular}

This thus allows us to investigate to what extent the past relationships among levels of the various stock prices significantly influence some countries.

Note that in all cases, the 5\% critical value is approximately 3.84 . The results are easily interpreted. 
Published in : Journal of applied entomology (2005), vol.129, iss. 1, p. 6-11

Status : Postprint (Author's version)

From the first column of Table 5 we immediately see that two of our five stock prices do not enter significantly into the cointegrating vector. These are the stock prices of Singapore and New Zealand. These results could have been expected as these two countries have relatively less financial importance in comparison with the other three countries in our sample.

With respect to long-run Granger (non)causality relations, it appears that the cointegrating vector, hence the long-run 'equilibrium" relationship between the stock prices, essentially enters the equations for the three Asian markets (see Table 5, second column). The latter results can be due to the geographical separation between the Asian and the Pacific markets. For both Australia and New Zealand, one cannot reject the hypothesis that the reintegrating vector is not significant, This gives some nice empirical support to the notion of rather separated financial markets in the Pacific-Basin areas.

As pointed out above, we based this analysis on one cointegrating vector, and hence four common stochastic trends. As shown in Table 4, a second reintegrating vector would only be significant at a $15 \%$ level. However, one must recall that the behaviour of Johansen's reintegration tests is theoretically valid only under i.i.d. Gaussian innovation. As our data are more than likely to display substantial conditional heteroskedasticity of the GARCH type, see Corhay and Tourani Rad (1993), one should be cautious on the number of reintegrating vectors to select, although in analogy to the behaviour of unit root tests (see Haldrup,

1992; Kim and Schmidt, 1992; Urbain, 1991) one should not expect too serious size and power distortions.

If we nevertheless analyse briefly the behaviour of the second vector given by the second column of the $\beta$ matrix in Table 4 , we see that it reads approximately as $(0,0,1,-1)$, i.e. a long run relationship involving only the Pacific countries Australia and New Zealand.

An LR test, under the maintained assumption of two cointegrating vectors, points out (calculated tests statistics is 0.17 well below the $5 \%$ critical values of a $\chi^{2}(2)$ ) that with two vectors, the cointegrating space is well described on the one hand, by a vector of the general form similar to above with all countries except Singapore and New Zealand and on the other hand, by a second vector whose components are given by $(0.0 .0 .0,0.0,-1.25,1.0)$. Although this last point would require further investigation, it tends to emphasize the existence of a rather integrated general Pacific-Basin area where the regional aspects (Asian versus Pacific Basin) have important roles to play.

\section{Conclusions}

In this paper, we investigated the long-run relationships among a set of five major Pacific-Basin stock markets. We have focused on the common long run behaviour of their stock price indices over a sample period of 20 years. Using multivariate cointegration analysis, we find that there exists a rather integrated Pacific-Basin financial area. However, a detailed analysis of the long-run relationships among the stock prices enable us to argue that the regional aspects (Asian versus Pacific) play important roles.

From a methodological point of view, several extensions are desirable such as using the estimates obtained in this study to estimate the common trends. A second interesting issue which remains in our research agenda is to try to investigate jointly the common trending behaviour and the common volatile behaviour of the stock prices in a unified framework. To our knowledge, this would require a new and a different theoretical framework and is therefore left for further research.

\section{Note}

${ }^{1}$ In this presentation we have omitted deterministic components including constant, trends, etc. for convenience.

\section{References}

Baily, W. and Stulz, R. (1990) Benefits of international diversification: the case of Pacific Basin stock markets. Journal of Portfolio Management, Summer, 7-61.

Banerjee, A. and Hendry, D. F. (1992) Testing for integration and cointegration: a review, Oxford Bulletin of Economics and Statistics, 54(3), 225-56. 
Published in : Journal of applied entomology (2005), vol.129, iss. 1, p. 6-11

Status : Postprint (Author's version)

Brennan, M. J. and Schwartz, E. S. (1986) Asset pricing in a small economy: a test of the omitted assets model, in G. Bamberg and K. Spremann (eds.) Capital Market Equilibria, Springer-Verlag, Berlin.

Campbell, J. Y. and Hamao. Y. (1990) Predictable slock returns in the United States and Japan: a study of long-term capital market integration, NBER working paper 3191,

Clio, D. C. Eun, C. S. and Senbet, L. W. (1986) International arbitrage pricing theory: an empirical investigation. Journal of Finance, 41, 313-30.

Corhay, A. and Tourani Rad, A. (1993) Conditional heteroscedasticity in Pacific-Basin stock markets returns, in T. Bos and T. Fetherson, (eds.) Research in International Business and Finance, Rising Asian Capital Markets: Empirical Studies, JAI Press. 3278.

Corhay, A.. Tourani Rad, A. and Urbain, J.-P. (1993) Common stochastic trends in European stock markets, Economic Letters. 42, 385-90.

Corhay, A.,Tourani Rad, A. and Urbain, J.-P. (I992)GARCH and cointegration models for European stock prices, in A. M.

Fatemi (ed.) Proceedings of the Third ITFA meeting, Chapter 11, Laredo State University Press, Texas.

Cumby, R. E. (1990) Consumption risk and international equity returns: some empirical evidence. Journal of International Money and Finance, 9, 182-92.

Dickey, D. A. and Fuller, W. (1979) Distribution of the estimators for autoregressive time series with a unit root. Journal of the American Statistical Association, 74, 427-31.

Dickey, D. A. and Fuller. W. (1981) Likelihood ratio test statistics for autoregressive time series with a unit root. Econometrica, 49, 1057-72.

Dolado, J., Jenkinson, T. and Sosvilla-Rivero, S. (1990) Cointegration and unit roots: a survey. Journal of Economic Surveys, 4(3), 249-73.

Engle, R. F. and Granger, C. W. J. (1987) Co-integration and error correction: representation, estimating and testing, Econo- metrica, 55, 251-76.

Errunza, V. and Losq, E. (1985) International asset pricing under mild segmentation: theory and test, Journal of Finance, 40, 10524.

Eun, C. S. and Shim. S. (1989) International transmission of stock market movements. Journal of Financial and Quantitative Analysis. 24, 241-56.

Fuller, W. A. (1976) Introduction to Statistical Time Series, John Wiley and Sons, New York.

Gultekin, N. B., Gultekin, M. N. and Penati. A. (1989) Capital control and international capital markets segmentation: the evidence from the Japanese and American stock markets, Journal of Finance, 44, 849-69.

Haldrup, N. (1992) Heteroskedasticity in non-stationary time series, some Monte Carlo evidence. Meто 1992-8,

Aarhus University. Hamao, Y., Masulis. R. and Ng. V. (1990) Correlation in price changes and volatility across international stock markets, Review of Financial Studies, 3, 281-307.

Harvey, C. R. (1991) The world price of covariance risk. Journal of Finance, 46, 111-58.

Jeon, B. N. and von Furslenberg, G. M, (1990) Growing international co-movemenl in stock price indexes. Quarterly Review of Economics and Business, 30, 15-31. 
Published in : Journal of applied entomology (2005), vol.129, iss. 1, p. 6-11

Status : Postprint (Author's version)

Johansen, S. (1988) Statistical analysis of co-integration vectors, Journal of Economic Dynamics and Control, 12, 231-54.

Johansen, S.( 1991) Estimation and hypothesis testing ofcointegration in vectors Gaussian autoregressive models, Econometrica, 52, 1551-80.

Johansen, S. (1992) Cointegration in partial system and the efficiency of single equation analysis. Journal of Econometrics, 52, 389-402.

Johansen. S. and Juselius. K. (1990) Maximum likelihood estimation and inference on cointegration with applications to the demand for money, Oxford Bulletin of Economics and Statistics, 52, 169-210.

Kasa, K. (1992) Common stochastic trends in international stock markets, Journal of Monetary Economics, 29, 95-124.

Kim. K. and Schmidt, P. (1992) Unit roots tests with conditional heteroskedasticity, mimeo, Michigan Stale University.

King, M. A. and Wadhwani. S. (1990) Transmission of volatility between stock markets, Review of Financial Studies, 3, 5-33.

Newey, W. K. and West, K. D. (1987) A simple positive definite. heteroskedasticity and autocorrelation consistent covariance matrix, Econometrka, 55, 703-708.

Park, J. and Fatemi, A. M. (1993) The linkage between the equity markets of Pacific-Basin countries and those of the US, UK and Japan: a vector autoregression analysis, forthcoming in Global Finance Journal.

Perron, P. (1988) Trends and random walks in macroeconomic time series: further evidence from a new approach. Journal of Economic Dynamic and Control, 12, 297-332.

Phillips, P. C. B. (1987) Time series regressions with a unit root, Econometrica, 55, 277-301,

Phillips, P. C. B. and Perron, P. (1988) Testing for a unit root in time series regression, Biometrika, 75, 335-46.

Solnik, B. H. (1974) Why not diversify internationally rather than domestically? Financial Analyst Journal, 30, 48-54,

Solnik, B. H. (1991) International Investment. 2nd Edition, Addison Wesley.

Stehle, R. E. (1977) An empirical test of the alternative hypotheses of national and international pricing of risky assets, Journal of Finance, 32, 493502.

Stock, J. and Watson, M. (1988) Testing for common trends, Journal of the American Statistical Association, 83, 1097-107,

Urbain, J. -P. (1991) The behaviour of unit roots tests in the presence of conditional heteroskedasticity, CREDEL Research Paper 9104, Universite de Liege.

Urbain, J. P. (1992) On weak exogeneity in error correction models, Oxford Bulletin .of Economics and Statistics, 54, 187-208.

Weatley, S. (1988) Some tests of international equity integration, Journal of Financial Economics, 21, 177-212. 